\title{
El centro histórico como proyecto y objeto de deseo
}

\section{Introducción}

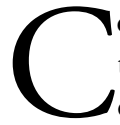
on este artículo se presentan algunas hipótesis e ideas respecto de la relación entre el centro histórico, el espacio público y los grandes proyectos urbanos (GPU), partiendo del entendido que el centro histórico es un espacio público por excelencia, y por tanto, un elemento articulador de la ciudad, lo cual le convierte-por sí y ante sí- en un GPU. Esta propuesta se desarrolla en el contexto optimista de la ciudad como solución y en la consideración del centro histórico como objeto del deseo. Para desarrollar esta idea se parte de los siguientes tres principios orientadores.

Primero, es necesario partir con una visión optimista de la ciudad en el sentido de que la ciudad es menos un problema y más una solución. Y esta visión tiene que ver con la necesidad de superar el estigma y pesimismo que se ha hecho de ella, en un doble sentido: por un lado, como si fuera una fuente de anomia y caos que se expresa, por ejemplo, en una condición de selva de cemento, en una fuente que genera violencia o en un espacio creador de pobreza (neomaltusianismo), y por otro, en el decreto de muerte que se hace periódicamente de la ciu$\mathrm{dad}^{1}$. De estas concepciones negativas sobre la ciudad se llegó a pensar que para resolver estos problemas había que detener el proceso de migración del campo a la ciudad para que no siguiera creciendo, y para de esa manera, detener los problemas.

\footnotetext{
* Coordinador del Programa de Estudios de la Ciudad de FLACSO. E-mail: fcarrion@flacso.org.ec.

1 "¿La ciudad ha muerto? Ahora es la globalización la que la mata. Antes fue la metropolización que se desarrolló con la Revolución Industrial. Y antes fue la ciudad barroca, que se extendió fuera del recinto medieval. Periódicamente, cuando el cambio histórico parece acelerarse y es perceptible en las formas expansivas del desarrollo urbano, se decreta la muerte de la ciudad" (Borja, 2003, p. 23).
}

A estas alturas de este siglo, y después de haber tenido un acelerado proceso de urbanización en América Latina ${ }^{2}$, se puede afirmar sin temor a equivocación que en las ciudades se reduce la pobreza, al menos desde la perspectiva de las necesidades básicas insatisfechas (NBI). Según Jordán y Simioni (2002, p. 15), "en todos los países la pobreza tiende a ser mayor en las áreas rurales que en las urbanas, y tiende a ser menor en las ciudades más grandes que en las intermedias y pequeñas [...] Por el contrario, en la mayoría de los países la concentración urbana no ha sido un factor negativo, pues ha permitido el acceso a bienes y servicios en una medida bastante mayor que la prevaleciente en tiempos de predominio rural".

Por otro lado, en las ciudades es más factible cambiar los patrones inequitativos de género que en el campo (Arboleda, 1999), porque mientras en éste están asentadas las tradiciones culturales que le asignan roles asimétricos y específicos a la mujer, en la ciudad ella se hace pública, se hace libre.

Un segundo punto que guía la exposición se refiere al hecho que en América Latina se está viviendo una revalorización de la ciudad construida, y dentro de ella, con un grado aún mayor, de los dos tipos de centralidad: la histórica y la urbana-que en algunos casos coinciden-, en un contexto de internacionalización. Esta revalorización tiene, entre otros, dos determinaciones explícitas: el proceso de globalización y la transición demográfica.

2 "Tomando nota del alto grado de urbanización alcanzado por la región, el Plan de Acción Regional se propuso el reto de transformar esta característica en una ventaja, en vez de seguir considerándola un problema como fue el discurso habitual en la década anterior" (Mac Donald y Simioni, 1999, p. 7). 
El regreso a la ciudad construida se debe a que el proceso de globalización introduce, por ejemplo, dos variables significativas a nivel urbano: por un lado, la reducción de los territorios distantes, el cambio en las velocidades de las ciudades y la disminución de los desplazamientos de la población por la introducción de las nuevas modalidades de la cultura a domicilio, entre las que se puede mencionar el tele-trabajo, el cine y la comida; y por otro, el que los ámbitos de socialización fundamentales se realizan en espacios públicos significantes como las centralidades o los llamados "artefactos de la globalización” (De Mattos, 2002).

La revalorización de la ciudad construida proviene también de la transición demográfica, que se explica por el hecho de que si en 1950 América Latina tenía una concentración de la población en ciudades que bordeaba el $41 \%$, a inicios del siglo XXI se ha llegado a una cifra cercana al $80 \%$ (HÁBITAT, 2000); lo cual significa que en un período de un poco más de 50 años se ha reducido significativamente la población en capacidad de migrar, del $60 \%$ que existía en 1950 a sólo el $20 \%$ que hay en la actualidad.

Este cambio demográfico tiene dos consecuencias directas para el análisis que interesa: por un lado, que las ciudades dejan de crecer en la forma acelerada que lo venían haciendo ${ }^{3}$, con lo cual se puede empezar a pensar menos en una ciudad de la cantidad y más en una de la calidad, y por otro, que se cierra del ciclo de la migración del campo a la ciudad y se abren nuevas formas de migración, como la internacional y la peri-urbana. La migración internacional da lugar al nacimiento de las segundas, terceras y cuartas ciudades de nuestros países por fuera de los territorios nacionales, e incluso, de América Lati$n a^{4}$. Pero también a que la región reciba un flujo de recursos económicos por concepto de remesas no inferior a los treinta mil millones de dólares como promedio anual (Avalos, 2002).

La globalización y transición demográfica conducen a la existencia de un doble movimiento

\footnotetext{
${ }^{3}$ En 50 años la tasa de urbanización de la región se reduce a la mitad: pasa de $4,6 \%$ anual en 1950 a $2,3 \%$ en el año 2000.

${ }^{4}$ Allí están los casos de República Dominicana o El Salvador con Nueva York, de Cuba con Miami y de México con Los Angeles, entre otros.
}

interrelacionado en la ciudad: el regreso a la ciudad construida en un contexto de internacionalización, que lleva a la necesidad de introducir el concepto de introspección cosmopolita como rasgo distintivo de la actual urbanización en América Latina, diferente al del período anterior caracterizado por la periferización y la formación de áreas metropolitanas.

En el contexto de estos cambios que está sufriendo la ciudad en América Latina, la centralidad histórica debe readecuarse a las nuevas funciones, para lo cual recurre a la promoción y construcción de GPU. En esta re-adecuación a los polos de punta del desarrollo urbano, se requieren enormes inversiones que le pongan al día dentro de la ciudad, de tal manera que no sea un freno y sí un motor de aceleración. En el centro histórico de Quito se tiene una inversión anual promedio no menor a los 20 millones de dólares, en La Habana una cifra parecida y en México una cantidad superior. Y en los tres casos la inversión es creciente.

Y aquí aparece la doble condición que guía el presente trabajo: el centro histórico es el espacio público por excelencia de la ciudad, y por ello, se debe convertir en la plataforma de innovación del conjunto de la urbe y en objeto del deseo de la ciudad posible; es decir, la centralidad histórica debe ser entendida como proyecto y no sólo como memoria.

Para desarrollar esta propuesta, se seguirá una lógica expositiva donde se tratarán los siguientes aspectos: primero se formularán tres hipótesis respecto del destino de los centros históricos: el fin de los centros históricos, las nuevas centralidades históricas y el fortalecimiento de la centralidad para -en esta última hipótesis- concebirlo dentro del deber ser a partir de su consideración como GPU. Luego se desarrollará la propuesta del centro histórico como el espacio publico por excelencia de la ciudad, que viene de la simbiosis (encuentro), lo simbólico (identidades) y la polis (ć́vico), y que como tal, debe volver a ser el elemento estratégico de la estructura de la ciudad. En tercer lugar, se busca presentar al centro histórico como proyecto, como el GPU que le permita convertirse - desde sus raíces históricas y culturales- en el elemento transformador de la ciudad en su conjunto. Finalmente, se presentarán algunas conclusiones surgidas de estas reflexiones. 
En otras palabras, el momento que se vive dentro del patrón de urbanización en la región - de "introspección cosmopolita”, producto de la globalización y la transición demográfica-valoriza el significado y función de los centros históricos, lo cual permite pensar en el futuro de éstos en un contexto optimista de la ciudad. Es decir, concebir al centro histórico como un proyecto de deseo.

\section{Hipótesis sobre el futuro de los centros históricos}

En América Latina el patrón de urbanización ha entrado en un franco proceso de transformación; si en la década de los '40 la urbanización se dirigió hacia la expansión periférica, en la actualidad lo hace hacia la ciudad existente: se pasa de una tendencia exógena y centrífuga del desarrollo urbano hacia una endógena y centrípeta. Es una urbanización que transita del tradicional concepto de ciudad frontera a otro de ciudad en red.

Con esta vuelta de prioridad a la urbe construi$\mathrm{da}^{5}$, el centro histórico cobra un peso singular y su naturaleza cambia; se plantean nuevos retos vinculados a las accesibilidades, a las centralidades intraurbanas, a las simbologías existentes y a las relaciones sociales que le dan sustento; se revaloriza la centralidad histórica y se plantea el reto de desarrollar nuevas metodologías, técnicas y conceptos que abran nuevas perspectivas analíticas y mecanismos de intervención que superen los paradigmas monumentalistas.

¿Qué puede pasar con los centros históricos en este contexto, si tenemos en cuenta que son un producto histórico que nace, se desarrolla y muere, como todo proceso social? También es necesario interrogarnos respecto del destino que pueda tener la transformación y re-funcionalización de la centralidad histórica en relación al conjunto de las estructuras urbanas $^{6}$.

\footnotetext{
${ }^{5}$ Que exige políticas y acciones urbanísticas dentro de la ciudad, es decir, urbanización de la ciudad o re-urbanización.

6 "Conservar un centro histórico quiere decir transformar la ciudad sobre la ciudad, con el fin de evitar la pérdida de centralidad de éste" (Bohigas, 1997, p. 130).
}

Intentar responder estas preguntas lleva a formular tres hipótesis respecto de su posible devenir, que en la realidad son más una combinación de ellas que las mismas en estado puro (aunque siempre existe una con mayor peso sobre las otras). Pero independientemente de las hipótesis planteadas, los centros históricos están viviendo una dinámica que hace pensar que su futuro está en juego y que en mucho dependerá de las políticas que se diseñen, más aún si no se reconoce las limitaciones que tienen los enfoques conservacionistas y desarrollistas. En la primera hipótesis se privilegia lo antiguo bajo denominaciones historicistas, y en la segunda hay una negación de lo antiguo por lo nuevo que se fundamenta en el "fin de la historia", porque la renovación se vacía de referentes históricos.

Estas hipótesis son las siguientes:

\subsection{Podemos estar viviendo el fin de los centros históricos}

Si partimos por la opción más negativa y pesimista, se puede plantear que los centros históricos se están muriendo. La hipótesis del fin de la centralidad histórica se sustenta, por un lado, en el principio de que todo proceso histórico evoluciona desde su nacimiento hasta su probable fallecimiento, y por otro, en el hecho histórico de que su nacimiento está asociado con el signo de la crisis y con la muerte venidos del proceso de diferenciación entre centro urbano y centro histórico, donde el primero extrae las funciones de centralidad al segundo y-en ese proceso- el segundo termina degradándose por la pérdida o vaciamiento de las funciones centrales.

"El nacimiento de la centralidad histórica se produce en el momento en que entra en decadencia. Esto es, que ve la luz con el estigma de la crisis y que, por tanto, una de las características esenciales de los centros históricos es que nacen con su muerte a cuestas. Tal crisis nace por la disfuncionalidad urbana, por el deterioro de la centralidad, por la reducción de los tiempos, por la concentración de la pobreza, por los problemas ambientales, entre otros. Es importante remarcar este hecho, porque desde su nacimiento -por tanto, desde su crisis- lleva el signo de la oportunidad, pero no sólo para esta parte importante de la ciudad, sino para la ciudad toda. Por eso la renovación encara más un sentido de futuro que 
de reconstrucción de las condiciones iniciales" (Carrión, 2001, p. 64).

El vaciamiento de las funciones de los centros históricos empieza a ocurrir cuando dejan de ser la ciudad toda, y como tal, comienzan a perder la diversidad propia de toda urbe. Es el crecimiento de la ciudad el que lleva a esta superación y también a que sea un continente del centro histórico en nacimiento. El momento en que los centros históricos pierden las funciones de centralidad empiezan a morirse, requiriendo como contraparte la renovación ${ }^{7}$. Los centros históricos se pueden erosionar o vaciar a través de varias vías.

Así, se deterioran por la salida de las funciones de representación política, que reducen - por ejemplo- su condición de constructor de identidades, integraciones e imaginarios sociales. Cuando salen los órganos de representación política se pierde centralidad y representación en ámbitos superiores al propio centro histórico. Así tenemos que con la reubicación de las actividades de la Presidencia de la República se pierden las funciones de representación e integración políticas más importantes de un centro histórico, de una ciudad y de un país: la democracia: allí están los casos aleccionadores de México y Cuba, que fueron reubicados dentro de la ciudad, y el caso extremo de Río de Janeiro, que se produjo por fuera de la misma urbe.

Se pierden también por la reubicación de ciertas funciones mercantiles a través del traslado de las casas matrices a las nuevas centralidades (aunque en algunos casos se mantienen en el centro las sucursales), de la creación de las firmas económicas de punta por fuera del centro histórico y de la precarización del comercio, la industria y los servicios por causa de la informalización de las actividades económicas.

Los centros históricos pierden centralidad cuando se homogenizan, por ejemplo, al inclinar la balanza de la contradicción estructural entre riqueza histórica-cultural y pobreza social-económica a través del turismo o la pobreza. En el primer caso, la prioridad de la actividad turística, justificada como

${ }^{7}$ Renovación en el sentido de un nuevo orden sustentado en la continuidad histórica y no un renacimiento, porque además que no ha muerto, puede ser el pretexto de un desarrollo desde ninguna base histórica pre-existente. mecanismo de internacionalización y desarrollo económico no contaminante (industria sin chimeneas), es revelada como todo lo contrario: es un sector altamente contaminante de la cultura, la economía, la política, la arquitectura y el urbanismo, lo cual debe ser repensado desde la óptica multicultural y definido en las políticas de renovación. Pero también uniformiza bajo la forma de la gentrificación de actividades (no sólo residencial), sin reducir la pobreza; antes bien, expulsándola.

En el segundo caso, la pobreza acumulada, en tensión con la riqueza histórica, está llevando a su conversión en un reducto de la pobreza, con lo cual los centros históricos "de pobres" se convierten en centros históricos "pobres", y la contradicción estructural más significativa -entre la riqueza histórica-cultural opuesta a la pobreza social-económica- termina por inclinar la balanza hacia la erosión de la riqueza, porque la pobreza opera como un Rey Midas al revés: todo lo que topa lo erosiona. El inquilinato bajo la forma del tugurio o el comercio callejero que privatiza el espacio público y la prostitución, entre otros, son muestras evidentes de esta afirmación.

Los centros históricos también pierden su condición de centralidad cuando se reduce su accesibilidad, velocidad y articulación con la ciudad, por ejemplo, con las peatonizaciones, con el rezago tecnológico, con la ruptura de las redes sociales y con la poca conectividad ${ }^{8}$.

Pero los centros históricos no sólo pierden centralidad por estos procesos generales, sino también por las políticas urbanas incorrectas. Se vacían de sociedad por las políticas monumentalistas que tienden a privilegiar el denominado "patrimonio físico", poniendo como destino de la intervención el pasado y disminuyendo el rico capital social existente, y por las políticas desarrollistas que arrasan con el pasado, incrementan los precios del suelo y fortalecen la gentrificación.

Ejemplos de centros históricos que pierden su centralidad para transformarse en áreas o barrios históricos son San Telmo en Buenos Aires o La Cande-

${ }^{8}$ Plantearse el tema de la tecnología de punta para los centros históricos es una forma central de reconstituir la competitividad, conectividad y posicionamiento perdidos, y por otro lado, replantear el tema de su valor de historia. 
laria en Bogotá; también se debe mencionar a Santo Domingo en República Dominicana o Cartagena en Colombia, que han tenido una propuesta única vinculada al turismo que les lleva a operar operando más como enclaves históricos. Están además aquellos que empiezan a vaciarse de sociedad debido a que pierden aceleradamente población residente (Quito, Santiago). En suma, con la pérdida de centralidad los centros históricos se transforman en lugares o barrios históricos y dejan de ser lo que son: centros, porque se han periferizado.

\subsection{Podemos estar viviendo el aparecimiento de otras formas de centralidad}

La hipótesis del aparecimiento de nuevas y novedosas formas de centralidad histórica se asienta sobre la base de las siguientes vías.

Una primera, que vive la transformación del centro histórico de un espacio de encuentro hacia otro de los flujos ${ }^{9}$. Un caso interesante para analizar es el de la formación de las centralidades longitudinales, donde la centralidad no es un punto concéntrico sino una sucesión de puntos en línea. Dos tipos de casos ilustran la afirmación: por un lado, lo que ocurre en Bogotá -a partir del sistema de transportación Transmilenio, que estructura un conjunto de espacios públicos colindantes sobre la base de este eje; $y$ por otro, en La Paz, donde se configura desde su centro histórico hacia la Av. El Prado, así como en la Ciudad de México, donde se desarrolla desde su centro histórico hacia la Av. Reforma.

Una segunda vía es aquella que surge de la integración de diversas centralidades, originarias cada una de ellas en distintos momentos históricos de la ciudad bajo la modalidad continua o en red. Se puede señalar el caso de Quito, donde el centro histórico, que fue el lugar fundacional de la ciudad -y por tanto de origen colonial-, se articula con la centralidad urbana de la llamada Mariscal Sucre, nacida a mediados del siglo XX. Hoy en día estas dos centralidades se dan la mano para conformar una nueva donde la tecnología, los tiempos y las funciones son distintos, pero que se articulan extensivamente como una nue-

\footnotetext{
9 Siguiendo a Castells (1999), en el sentido de que estaríamos viviendo el paso del espacio de los lugares al de los flujos.
}

va forma de centralidad continua. Lo mismo ocurre, pero por conurbación, entre el centro histórico de la Ciudad de México cuando se vincula con los de Coyoacán y Xochimilco.

Una tercera vía está referida a la existencia de centralidades discontinuas espacialmente. ¿Cómo entender los centros históricos en espacios discontinuos que están más allá de las fronteras definidas a través de contenidos físicos? Con los procesos de globalización y de migración internacional empiezan a desarrollarse un conjunto de centralidades simbólicas de -por ejemplo- los emigrantes que integran la ciudad "de adentro" con la ciudad "de afuera”. En Ecuador, el centro histórico de la ciudad de Cuenca se integra con la ciudad de Murcia a través del Parque del Retiro, donde se concentran los ecuatorianos para los intercambios económicos y culturales, así como para constituir redes sociales y establecer vínculos espaciales discontinuos propios de las comunidades simbólicas en espacios sociales transnacionales (Beck, 1998). Lo mismo ocurre en Lima, con la plaza de la Constitución en Santiago, o en Managua, con la plaza de la Merced en San José. Esto significa que las centralidades están articuladas social, cultural y económicamente sin que exista un espacio continuo.

Una cuarta alternativa de centralidad histórica es aquella que se inscribe en la definición de los no lugares (Augé, 1998), propia de la globalización. Puede ser una centralidad que se construye en la periferia con tecnología de punta y accesibilidad altamente diferenciada y excluyente. Los ejemplos más emblemáticos e interesantes son los casos de la centralidad construida en la periferia de la Ciudad de México bajo el nombre de Centro Corporativo Santa Fe, o el del Centro Berrini en San Pablo. Aquí aparece una nueva forma de centralidad que también es histórica a pesar de su bajo valor de antigüedad, pero que es ordenadora de la ciudad y de su desarrollo urbano.

También se pueden mencionar aquellos lugares centrales de menor escala pero altamente especializados y fragmentados, que aparecen bajo las formas de artefactos de la globalización (De Mattos, 2002), como pueden ser los ejemplos de los aeropuertos (Río de Janeiro), los puertos (Valparaíso), los World 
Trade Center ${ }^{10}$ (Bogotá), los malls (Lima), los estadios (Buenos Aires), los centros de convenciones (Cartagena) y ferias (San Pablo), los parques temáticos (Ciudad de México) y los centros de negocios $\left(\right.$ Santiago $\left.{ }^{11}\right)$, entre otros.

Y por último, una quinta posibilidad es la centralidad virtual, donde los portales de Internet cumplen el rol de una centralidad difusa carente de referencias territoriales.

\subsection{Fortalecimiento de la centralidad histórica}

La tercera hipótesis es la del fortalecimiento de los centros históricos, la cual aparece más como proyecto y deseo que realidad, y parte del principio de que el fortalecimiento de la centralidad histórica será posible si se lo considera integralmente desde las tensiones riqueza-pobreza, local-global y centralidad histórica-urbana (Carrión, 2001), y desde las siguientes condiciones.

El centro histórico debe asumir su condición pública a partir de la reconstrucción de su doble dimensión: en primer lugar, como espacio público que permite la renovación no sólo del ámbito que lo contiene, sino del conjunto de la ciudad ${ }^{12}$, porque es el espacio que integra y organiza. El urbanismo se debe organizar a partir de lo público y no de lo privado, de lo colectivo y no de lo individual. Ejemplos interesantes son la fundación de las ciudades españolas en el Nuevo Mundo. En 1523 el Rey Carlos I de España dictó una ordenanza que determinaba que la estructura urbana debía ser definida por sus plazas, calles y solares, comenzando desde la Plaza Mayor. De allí y hacia ella convergían las calles

\footnotetext{
${ }^{10}$ Existen en más de cien países y representan una forma emblemática de presencia de la globalización en el territorio urbano (ver www.worldtradecenter.org).

${ }^{11}$ La Ciudad Empresarial de Santiago es un ejemplo interesante, que además se denomina a sí misma como "ciudad" y no como centralidad de negocios. Está localizada en la zona norte de la ciudad, en la comuna de Huechuraba.

${ }^{12}$ La renovación urbana de La Habana Vieja ha permitido que se convierta en la plataforma de innovación no sólo de la ciudad de La Habana, sino también de Cuba, porque se la ha concebido como espacio público que estructura el conjunto de las funciones, usos de suelo y actividades de la ciudad (ver Carrión, 2004).
}

que unían a otras tantas plazas y plazuelas, a partir de las cuales se distribuían los solares de manera que el crecimiento de la población pudiera siempre proseguir la misma forma y lógica. En otras palabras, la ciudad se organizaba desde el espacio público, desde la Plaza Mayor, que conjuntamente con otras plazas, cumplían la función de "centralidad" de la ciudad, gracias a las condiciones de espacio público que tenían (Carrión, 2004).

Y en segundo lugar, como objeto público de gobierno, para que recupere y revierta el deterioro histórico de la función pública. Lo que hoy se considera centro histórico fue la ciudad toda, y por tanto, tuvo su gobierno propio; pero cuando la ciudad creció este gobierno perdió la exclusividad sobre esta parte, empezando el deterioro del gobierno de esta parte importante del centro histórico. Por eso, una importante consideración para fortalecer los centros históricos es tener un órgano de gobierno autónomo, representativo y legítimo.

Es imprescindible tener una visión económica del centro histórico que genere las condiciones de posicionamiento, competitividad y conectividad a través de la incorporación de las tecnologías de punta y de la reconversión productiva (artesanía, servicios, industria), en un contexto de modernización que añada más valor y tiempo al pasado; es decir, un proceso que sume valor histórico a la centralidad. Si se quiere que un centro histórico sea lo que originalmente fue, lo que se conseguirá es congelarlo en el tiempo, pero si se sigue el camino de su historia-que son los espacios de mayor mutación dentro de la ciudad- se deberán plantear políticas de transformación, desarrollo y sustentabilidad, y no políticas de conservación y preservación.

Se requiere de políticas sociales (salud, educación, vivienda, empleo) en los centros históricos, porque si no la figura inversa del Rey Midas terminará por erosionar la gran riqueza histórica y cultural que tienen; de ahí la necesidad de redistribución de los recursos de la sociedad y de generar una mejora de las condiciones de vida de la población que allí reside, para que se produzca un ascenso social y no su expulsión. 


\section{El centro histórico como espacio público}

La ciudad es un espacio público (Bohigas, 1997) porque es de dominio público; es decir, es un espacio donde se expresan y se forman voluntades colectivas para que la sociedad se represente en sus derechos y deberes (ciudadanía). Es el lugar de encuentro de los diversos, donde se expresa la calidad de una ciudad y su urbanismo. Pero también, según Borja (2003), la ciudad es un conjunto de puntos de encuentro o un sistema de lugares significativos, tanto por el todo urbano como por sus partes. Es decir, la ciudad tiene puntos de encuentro y lugares significativos operando en un sistema para que pueda existir como tal.

Estos lugares de encuentro y puntos significativos son los espacios públicos, porque reúnen los siguientes tres componentes fundamentales: lo simbiótico, lo simbólico y la polis. El espacio público es un espacio simbiótico en el sentido que genera integración, articulación, encuentro y conectividad de los distintos y lo hace a partir de dos determinaciones: una que le da sentido y forma a la vida colectiva mediante la integración de la sociedad, y otra que le da un orden y unidad a la ciudad a través de su cualidad articuladora estratégica.

En ese contexto, el centro histórico es el espacio de encuentro por excelencia tanto por su condición de centralidad, que hace que sea un punto focal de la ciudad, como por la suma de tiempo al pasado que le permite adquirir un valor de historia. Por esta doble cualidad de espacialidad (centralidad) y temporalidad (historia), es el lugar de encuentro de una población que vive en espacios que lo superan (transterritorialidad) y también es el ámbito donde se encuentran distintas sociedades provenientes de distintos tiempos y momentos históricos (transtemporalidad $)^{13}$. Esta condición le asigna al centro histórico la cualidad simbiótica particular del encuentro de la pluralidad de espacios, tiempos y de sujetos patrimoniales, cuestión que permite intro-

\footnotetext{
${ }^{13}$ Esta es la base de la definición de patrimonio como herencia, la cual le otorga su doble dimensión: como espacio de conflicto y disputa de la heredad y como escenario de la transmisión generacional de una sociedad hacia otra, incrementando su valor de historia.
}

ducir el concepto de ciudadanía derivada ${ }^{14}$, en términos de que se encuentran sociedades distintas provenientes de momentos diferentes. El centro histórico trasciende el tiempo y el espacio, produciendo transmisión generacional y alteridad en comunidades simbólicas transnacionales.

El centro histórico como espacio público es un espacio simbólico porque tiene un patrimonio de símbolos que genera identidades múltiples, colectivas y simultáneas. La carga simbólica proviene de la doble condición que tiene como centralidad y como acumulación histórica, lo cual conduce a una carga identitaria que hace -en sentido figurado y real- que la ciudadanía se identifique y represente a partir de su cualidad funcional (centralidad) y de su sentido de pertenencia (historia) ${ }^{15}$. El poder simbólico que se concentra en el tiempo y el espacio es muy alto; es el más significativo de la ciudad, al extremo de que le imprime el carácter a la urbe toda.

Con el inmenso poder simbólico que tiene el centro histórico como espacio público, es el lugar donde la sociedad se visibiliza y se representa. De allí que, por ejemplo, la política encuentre en este lugar una forma de visibilización -por ejemplo de los indígenas ecuatorianos o bolivianos, de las Madres de Mayo en Argentina o de los zapatistas en México- y de representación institucional que se logra a partir de la presencia del Palacio de Gobierno, sea nacional o local. De igual manera, la función económica y la actividad religiosa alcanzan grados importantes de proyección social. Por eso es necesario que los centros históricos sean heterogéneos para que se potencien las múltiples y simultáneas formas de identidad.

Y también el centro histórico, como espacio publico, es el ámbito de la polis, porque es el lugar de la

\footnotetext{
${ }^{14}$ Entendemos como "ciudadanía derivada" a los derechos y deberes que se transfieren de un sujeto patrimonial constituido en un momento histórico hacia otro que se apropia socialmente en otro momento.

${ }^{15}$ Esta distinción entre identidades de pertenencia y de rol han sido propuestas por Jiménez (1999) y aplicadas por Villena (2003) para el análisis sociocultural del fútbol. Parece que en el caso de los centros históricos tienen mucha pertinencia, porque incluso se percibe una tensión entre los sujetos patrimoniales imbuidos prioritariamente en su identidad de rol (función), como puede ser el capital inmobiliario, con los sujetos patrimoniales que tienen más peso con la identidad de pertenencia, como pueden ser los inquilinos.
} 
ciudad de mayor disputa, tanto del poder simbólico del que es portador como de las políticas de modernización del Estado, entre lo público y lo privado. No existe otro lugar de la ciudad tan disputado, porque los sujetos patrimoniales se confrontan y se enfrentan construyendo ciudadanía.

Las centralidades urbana e histórica son los elementos fundamentales de todos los espacios públicos. Sin embargo, en América Latina hay un proceso de despoblamiento de la centralidad, tal como lo ilustran los casos de Bogotá, Quito, Santiago, Ciudad de México y Lima, entre otros. Contrariamente a este proceso existe una marea de población que va diariamente hacia ellos: en Quito, Lima y México van alrededor de 8 veces más personas de las que allí viven. ¿Por qué? Pues porque la centralidad es un espacio público que concentra información, formas de representación y mercados, además de organizar la vida colectiva y la ciudad. Por eso el espacio público por excelencia es la centralidad -urbana e histórica-, lugar desde donde se parte, donde se llega y desde donde se estructura la ciudad.

El centro histórico es un espacio público no por sus partes (visión monumentalista), sino por el gran significado público y colectivo que tiene el todo. Es un espacio de todos, porque le otorga un sentido de identidad colectiva a la población, pero en un contexto de disputa del poder simbólico. Es un ámbito de encuentro donde la población disputa, socializa e intercambia (bienes, servicios, información). Pero también lo es porque tiene un orden público altamente especializado y definido: por un lado, leyes, ordenanzas y códigos; y por otro, un marco institucional complejo que es capaz de producir una gestión pública de coacción, regulación y administración. En este espacio colectivo existe una apropiación pública, una forma de gestión pública, una mirada colectiva y unas identidades múltiples que provienen de distintos actores, tanto de adentro como de afuera de la zona, así como del ayer y del hoy.

Sin embargo, hoy la ciudad se organiza más desde la esfera de lo privado que de la pública. En la actualidad el mercado tiene mayor peso del que tenía, al extremo de que la gestión pública se le subordina, y el espacio público ha pasado de espacio estructurante a ser estructurado, residual o marginal, perdiendo sus funciones originales, o en algunos casos, siendo susti- tuidos por otros espacios más funcionales al urbanismo actual, como son el centro comercial o el club social. De esta manera, el espacio público -como las plazas- termina siendo, por un lado, un desperdicio para la lógica económica de la maximización de la ganancia, y por otro, un mal necesario para cumplir con las normas del urbanismo.

Estamos viviendo una agorafobia (Borja, 2003) que ataca a los centros históricos desde distintas maneras, como pueden ser la ruptura de la unidad a través de la intervención con proyectos aislados, la privatización de las formas de gestión (empresas, corporaciones), la presencia del gran capital (por ejemplo, Benetton en La Habana y Carlos Slim en México) y de la gentrificación de actividades de prestigio. Cada una de estas formas conducen a nuevas formas de construcción de identidades sobre la base del mercado, y por tanto, del consumo. La globalización homogeneíza, rompiendo la base de existencia del centro histórico.

Pero también se vive el tránsito de la ciudad segregada -típica de la primera modernidad-, donde las partes que conformaban la ciudad estaban integradas al todo a través del espacio público, hacia la ciudad fragmentada - propia de la segunda modernidad- donde existen constelaciones discontinuas de fragmentos espaciales (Castells, 1999), que terminan por diluir la unidad urbana ${ }^{16} \mathrm{y}$ dan lugar al aparecimiento del fenómeno de la foraneidad urbana. En la actualidad las ciudades están llenas de personas que no se encuentran en ningún lugar ${ }^{17}$, que han perdido el sentido de pertenencia a la urbe, que se han creado fronteras de distinto tipo (sociales, físicas, etc.) y que en sus desplazamientos cotidianos

${ }^{16}$ Existen barrios autárquicos cerrados (Cáceres y Sabatini, 2004), unidades de gobierno exclusivas (Santiago tiene 34 comunas autónomas), espacios públicos donde una Fundación Privada se reserva el derecho de admisión (Malecón 2000 en Guayaquil) y centralidades inaccesibles (Santa Fe), entre otros.

${ }^{17} \mathrm{El}$ encuentro en la escuela es imposible porque la persona que entra al sistema público terminará sin haberse encontrado con la que estudia en el sistema privado. Lo mismo ocurre con los sistemas de salud. El pobre irá al mercado y el rico al centro comercial. El obrero estará en la fábrica ubicada en la periferia y el propietario estará en su oficina en la centralidad. 
tienen que identificarse constante y continuamente frente a una autoridad de guardianía... privada.

El espacio público no puede cumplir una función marginal o residual, es necesario que vuelva a tener la función que siempre tuvo para que sea el espacio estratégico que le dé integración a la sociedad y estructura a la ciudad. Y como el centro histórico es el lugar que más cambia en la ciudad, así como el espacio público por excelencia -no por sus partes sino por el todo-, su función debe ser la de convertirse en una plataforma de innovación que le dé un nuevo sentido a la ciudad. Por todo ello debe convertirse en el gran proyecto urbano.

\section{El centro histórico como proyecto}

El centro histórico no debe pensarse como el regreso a lo que antiguamente fue o a lo que es en la actualidad. El centro histórico debe ser concebido con un sentimiento dirigido hacia un fin predeterminado; es decir, debe convertirse en un proyecto que asuma el sentido del futuro deseado. Por eso, proyecto $^{18}$ y deseo $^{19}$ van de la mano. De esta manera, el centro histórico debe renovarse a partir de un preconcepto que le permita convertirse en una propuesta-significativa y grande- como anticipación de resultados previstos y como forma de adelantarse concientemente al futuro. Es decir, debe convertirse en un objeto de deseo a partir de un sujeto social con voluntad conciente. Incluso, se podría afirmar que el centro histórico no existe en la realidad y lo que le confiere existencia es su condición de proyecto.

En las áreas centrales siempre se construyeron GPU, principalmente, por ejemplo, a través de iniciativas tendientes a mejorar su accesibilidad (vialidad), a adecuar los espacios a las nuevas demandas (comercio, estacionamientos), a rehabilitar edificios antiguos (monumentos) o a remplazar estructuras arquitectónicas por edificios en altura. En

${ }^{18}$ Según el Diccionario de la RAL, proyecto tiene, entre otras, las siguientes acepciones: "planta y disposición que se forma para la realización de un tratado o para la ejecución de algo importante" o "conjunto de escritos, cálculos y dibujos que se hacen para dar idea de cómo ha de ser y lo que ha de costar una obra de arquitectura o de ingeniería".

${ }^{19}$ Según el Diccionario de la RAL, deseo significa "movimiento afectivo hacia algo que se apetece". otras palabras, fueron intervenciones sectoriales aisladas e insuficientes que rompieron, en muchos casos, con la continuidad histórica. Hoy, por las nuevas concepciones imperantes y por los resultados precarios evidenciados por este tipo de acciones, las áreas centrales históricas deben ser vistas en su totalidad como un gran proyecto urbano ${ }^{20}$.

Hay que tomar en consideración que las más importantes transformaciones urbanas se desarrollaron históricamente sobre la base de grandes proyectos. Eso quiere decir que los grandes proyectos no son nuevos en el urbanismo, porque han existido siempre en contextos históricos particulares. Su escala varía desde los cambios que produce a nivel de barrio hasta su límite superior con la construcción de nuevas ciudades, como son los casos de Brasilia y Chandigar. Sin embargo, existe la lógica que lleva a creer que en momentos de quiebre histórico la ciudad debe cambiar y re-acondicionarse mediante grandes inversiones urbanas. En los últimos momentos se pueden encontrar dos coyunturas claves: la revolución industrial y la globalización.

Con la revolución industrial se vive una aceleración de la urbanización que lleva a la ejecución de grandes proyectos que buscan adecuar la ciudad a la industrialización ${ }^{21}$. El crecimiento de la población

${ }^{20}$ Los GPU de la segunda modernidad están inmersos en el marco de una política neoliberal de desarrollo urbano que ha cambiado la condición urbana de los períodos anteriores. Los efectos simultáneos de las transformaciones producidas por las NTIC, la aplicación de políticas neoliberales y la globalización económica, social y cultural han contribuido a una gran polarización espacial en torno a los grandes centros urbanos, al desarrollo de grandes obras de infraestructura y a la concentración de capitales inmobiliarios en GPU en partes específicas de la ciudad. Este período se caracteriza por un aumento de la segregación social y la extensión de la metropolización hacia zonas aledañas a un ritmo sin precedentes. El cambio de una economía manufacturera hacia otra de servicios ha incrementado el significado de los distritos centrales de negocios, y por eso, la necesidad de revitalizar los centros de las ciudades (Carmona, 2003)

21 "La revolución industrial y técnica provocó profundas transformaciones en el tejido de las ciudades históricas de Europa, pero también engendró una toma de conciencia marcada por un sentimiento de apego a los valores históricos y estéticos de los monumentos históricos y los sitios que son testimonio de una época compleja" (Bouchenaki, 2001, p. 11) 
por la migración del campo a la ciudad, el traslado de los medios de producción hacia los lugares de concentración de la demanda, la presencia del automóvil y el aparecimiento del acero y el hormigón conducen a la transformación de las periferias y las centralidades urbanas mediante grandes proyectos. Así, se pueden mencionar en la centralidad, por ejemplo, la construcción de grandes ejes y anillos viales (la renovación urbana de París con Haussmann) y la construcción de nuevos edificios (estaciones ferroviarias, almacenes, hoteles). Pero también en la periferia se construyen programas masivos de vivienda social.

Si a lo largo de la historia ha habido cambios provocados por la construcción de GPU, lo que queda por preguntar es, ¿qué es lo nuevo ahora con la globalización?

Un siglo después de la revolución industrial tenemos una nueva oleada de grandes proyectos urbanos que se sustentan en los cambios tecnológicos, en la nueva lógica de acumulación global (globalización), en la conversión de la ciudad en un actor político relevante y en un lugar estratégico para la acumulación neoliberal, propios de la segunda modernidad (Beck, 1998). En América Latina estamos viviendo estos procesos, a los que se suman las particularidades propias de la región, donde se destacan las transformaciones demográficas, los cambios en los marcos institucionales de gobierno de la ciudad y las nuevas formas de emigración de la población. De esta manera, la ciudad transita de su consideración como espacio de los lugares a uno de flujos, y el desarrollo urbano es concebido como incremento de la productividad de la ciudad, a través de la competitividad, conectividad y posicionamiento.

Se desarrollan cuatro tipos de GPU. Un primer tipo podría estar relacionado con el aparecimiento de nuevas ciudades nacidas en los lugares estratégicos de la globalización, como pueden ser ciertos cordones fronterizos entre México y Estados Unidos o entre Brasil y Argentina. También los puertos que obedecen a los nuevos posicionamientos estratégicos que surgen en la red urbana global o ciertas ciudades que si bien existían antiguamente, hoy día son totalmente distintas, al extremo de que se podría decir que han sido re-fundadas.

Un segundo tipo de GPU están en la línea del reciclaje y reconversión de las antiguas estructuras urbanas y arquitectónicas que vienen de un pasado industrial (la reconversión de la fábrica de papel Loreto y Peña Pobre en la Plaza Cuicuilco, en Ciudad de México), portuario (Puerto Madero en Buenos Aires), aeroportuarias (Cerrillos en Santiago) o las centralidades históricas (Centro Histórico de Quito). Hay una re-funcionalización de ciertas estructuras arquitectónicas degradadas para ponerlas a tono con la nueva modernidad: allí están, por ejemplo, una Central de Abastos convertida en centro comercial (Buenos Aires), una estación férrea transformada en centro cultural (Santiago), un convento se convierte en hotel (Cartagena, Cuzco, Santo Domingo), un hospital que alberga a un museo de la ciudad (Quito) y un conjunto de viviendas que se transforman en universidades (La Candelaria, Bogotá).

Un tercer tipo de GPU se refiere a la construcción de nuevas estructuras afines al momento, tales como los artefactos de la globalización: centros comerciales, aeropuertos, estadios, World Trade Center, que buscan posicionar a la ciudad en un lugar estratégico de la globalización.

Y finalmente, la reconversión de las viejas centralidades históricas (Malecón 2000), el desarrollo de las nuevas centralidades (Santa Fe en México, la Cité en Buenos Aires) y la formación de las centralidades extendidas (Transmilenio en Bogotá)

En el contexto de las políticas neoliberales, de la crisis del Estado nacional y del peso que logra el mercado en el desarrollo urbano, la planificación urbana pierde significación. La planificación física nacida en la revolución industrial cae en desuso y la planificación estratégica cede terreno. Frente a ello, y frente al pragmatismo reinante toman relevancia los GPU, que tienen una doble virtud: muestran resultados a corto plazo y se convierten en las locomotoras que jalonan otras iniciativas, que integran a la población y que generan múltiples identidades.

El desarrollo de los GPU cuestiona a la planificación urbana en sus distintas versiones (física, estratégica), porque las regulaciones son vistas como un freno para la competitividad y el posicionamiento, su diseño tarda y las propuestas de largo plazo son poco viables en un mundo altamente cambiante. Además, por su forma y contenido tecnocrático, generan una limitación social importante: no logran 
producir adhesiones sociales. La crisis de la planificación urbana viene también de la mano de la crisis de lo público y de los pocos resultados obtenidos. Sin embargo, no deben ser vistas como antagónicas, sino como actividades complementarias.

Esto supone, como punto de partida, considerar al centro histórico como espacio público objeto del deseo, que deberá reconstruir su gestión pública bajo la forma de un gobierno único. En este contexto, la planificación urbana aparece como demanda o reivindicación y el centro histórico como un GPU de alcance supra-local. El deterioro y subutilización de las áreas centrales sólo puede abordarse por medio de la acción pública, no sólo porque el sector público es el actor social responsable de procurar el bien común, sino también porque es el único con la capacidad de desarrollar una visión a largo plazo y posee los instrumentos necesarios para abordar el problema de coordinación que los actores privados enfrentan en estas áreas (Rojas, 2004).

\section{Conclusiones}

El centro histórico -como un todo- es el espacio público por excelencia de la ciudad, y por tanto, el elemento fundamental de la integración social y de la estructuración urbana. Como eso no ocurre en la actualidad, dado que existe una agorafobia, el centro histórico aparece como objeto del deseo y como proyecto de escala variable, según su significación patrimonial.

De esta conclusión matriz se desprenden otras de no menor valor, como son las siguientes: a) con el nuevo patrón de urbanización de introspección cosmopolita en América Latina, la ciudad construida adquiere una nueva función y un mayor peso en el conjunto de la urbe. Este hecho determina que las centralidades urbanas e históricas puedan asumir como proyecto y deseo- roles de encuentro (simbiótico), representación (simbólico) y disputa (polis) en términos sociales y urbanos; b) los centros históricos son espacios públicos que tienen elementos de integración social, que deben mejorar su accesibilidad múltiple para contrarrestar la foraneidad urbana, y de estructuración urbana, que deben recuperar la centralidad para proyectarse a la ciudad desterrando el fraccionamiento urbano; c) en el contexto histórico actual, los centros históricos se convierten en los lugares privilegiados de producción de memoria, intentando, de esta manera, romper con la uniformidad que busca imponer la globalización; en ese sentido, el centro histórico se convierten en un símbolo más de la resistencia identitaria local ${ }^{22}$, y además, en una plataforma de innovación de la ciudad toda, dado que es el espacio público estructurante que más cambia en la ciudad, y por ende, el que más tiempo acumula (valor de historia); d) los centros históricos son lugares cívicos donde la sociedad invisible se visibiliza y donde la alteridad se genera. De allí que se requiera de un organismo público que institucionalice este carácter cívico (representativo), que impulse su condición de GPU (legitimidad) y que rinda cuentas de sus actos (transparencia); y e) así como no hay ciudades sin ciudadanía, no existe ciudadanía sin Estado; por tanto, cualquier propuesta sobre el centro histórico tiene que estar presente esta tríada indisoluble: ciudadanía, ciudad y Estado. Sólo de esa manera se tendrá más ciudadanos para más ciudad, y a su vez, más ciudad para más ciudadanos.

En otras palabras, la importancia de los centros históricos radica en la posibilidad de preservar y potenciar la memoria, para generar sentidos de identidad por función y pertenencia, y de convertirse en plataforma de innovación del conjunto de la ciudad. Por eso es importante tener un sujeto social con voluntad conciente (planificación). Por eso es importante también la construcción de un gobierno único de carácter público (transparente, legítimo y representativo) que sea capaz de encarar este reto. Por eso, finalmente, es más un proyecto y un objeto de deseo que realidad.

\section{Referencias bibliográficas}

Arboleda, M. (1999). "Equidad de género: el campo municipal como espacio de derechos y políticas" (mimeo).

Augé, M. (1998). Los no lugares, espacios del anonimato. Barcelona: Gedisa.

22 "Ante los peligros reales de uniformidad y despersonalización del hábitat que conlleva el urbanismo moderno, la supervivencia de los conjuntos históricos reviste una importancia capital para cada pueblo que busque conservar su verdadera dimensión cultural y su individualidad" (Bouchenaki, 2001, p. 13). 
Avalos, A. (2002). "Migraciones e integración regional" (mimeo). Caracas: CAF.

Beck, U. (1998). ¿Qué es la globalización? Barcelona: Paidós.

Bohigas, O. (1997). Regeneración y futuro de los centros metropolitanos. Madrid: Empresa Municipal de Vivienda, Dirección de Rehabilitación.

Borja, J. (2003a). La ciudad conquistada. Madrid: Alianza.

Bouchenaki, M. (2001). "Organismos internacionales e instrumentos jurídicos para la preservación de los centros históricos". Carrión, F. (ed.), Centros históricos de América Latina y el Caribe. Quito: UNESCO-BID-SIRCHAL.

Cáceres, G. y F. Sabatini (eds.) (2004). Barrios cerrados en Santiago de Chile: entre la exclusión y la integración residencial. Santiago: Lincoln Institute of Land Policy/Instituto de Geografía, P. Universidad Católica de Chile.

Carmona, M. (ed.) (2003). Globalización, forma urbana y gobernabilidad. Valparaíso: Universidad de Valparaíso.

Carrión, F. (ed.) (2001). Centros históricos de América Latina y el Caribe. Quito: UNESCO/BID/ SIRCHAL.

(2004). "Pobres las ciudades de pobres" (mimeo). La Paz: OXFAM.
Castells, M. (1999). La era de la información. Barcelona: Siglo XXI.

De Mattos, C. (2002). "Transformación de las ciudades latinoamericanas: ¿impactos de la globalización?" EURE Revista Latinoamericana de Estudios Urbano Regionales, 28, 85: 5-10.

HABITAT (1996). La pobreza urbana, un reto mundial. La declaración de Recife. Recife: Hábitat.

Jiménez, G. (1999). "Materiales para una teoría de las identidades sociales". Valenzuela, J.M., Decadencia y ange de las identidades. México: El Colegio de la Frontera.

Jordán, R. y D. Simioni (2002). "Hacia una nueva modalidad de gestión urbana”. Las nuevas funciones urbanas: gestión para la ciudad sostenible. Santiago: CEPAL.

Mac Donald, J. y D. Simioni (1999). Consensos urbanos. Aportes del Plan de Acción Regional de América Latina y el Caribe sobre Asentamientos Humanos. Santiago: CEPAL.

Rojas, E. (2004). Volver al centro: la recuperación de las áreas centrales. Washington, D.C.: BID.

Villena, S. (2003). "El fútbol y las identidades". Alabarces, P. (ed.), Futbologias. Buenos Aires: CLACSO. 